\title{
BMJ Open Self-reported eating rate and metabolic syndrome in Japanese people: cross-sectional study
}

\author{
Satsue Nagahama, ${ }^{1,2,3}$ Kayo Kurotani, ${ }^{1}$ Ngoc Minh Pham, ${ }^{4}$ Akiko Nanri, ${ }^{1}$ \\ Keisuke Kuwahara, ${ }^{1}$ Masashi Dan, ${ }^{2}$ Yuji Nishiwaki, ${ }^{3}$ Tetsuya Mizoue ${ }^{1}$
}

To cite: Nagahama S, Kurotani K, Pham NM, et al. Self-reported eating rate and metabolic syndrome in Japanese people: cross-sectional study. BMJ Open 2014;4:e005241. doi:10.1136/bmjopen-2014005241

- Prepublication history for this paper is available online. To view these files please visit the journal online (http://dx.doi.org/10.1136/ bmjopen-2014-005241).

Received 11 March 2014 Revised 31 July 2014 Accepted 8 August 2014

\section{CrossMark}

${ }^{1}$ Department of Epidemiology and Prevention, Center for Clinical Sciences, National Center for Global Health and Medicine, Shinjuku-ku, Tokyo, Japan

${ }^{2}$ All Japan Labor Welfare Foundation, Tokyo, Japan

${ }^{3}$ Department of

Environmental and

Occupational Health, School

of Medicine, Toho University,

Tokyo, Japan

${ }^{4}$ Department of

Epidemiology, Faculty of Public Health, Thai Nguyen University of Medicine and Pharmacy, Thai Nguyen Province, Vietnam

Correspondence to Dr Satsue Nagahama; satsue_0323@hotmail.com

\section{ABSTRACT}

Objectives: To examine the association between selfreported eating rate and metabolic syndrome.

Design: Cross-sectional study.

Setting: Annual health checkup at a health check service centre in Japan.

Participants: A total of 56865 participants (41 820 male and 15045 female) who attended a health checkup in 2011 and reported no history of coronary heart disease or stroke.

Main outcome measure: Metabolic syndrome was defined by the joint of interim statement of the International Diabetes Federation and the American Heart Association/National Heart, Lung, and Blood Institute.

Results: In multiple logistic regression models, eating rate was significantly and positively associated with metabolic syndrome. The multivariable-adjusted ORs $(95 \% \mathrm{Cl})$ for slow, normal and fast were $0.70(0.62$ to 0.79 ), 1.00 (reference) and 1.61 (1.53 to 1.70), respectively, in men ( $p$ for trend $<0.001$ ), and 0.74 (0.60 to 0.91 ), 1.00 (reference) and 1.27 (1.13 to 1.43), respectively, in women ( $p$ for trend $<0.001$ ). Of metabolic syndrome components, abdominal obesity showed the strongest association with eating rate. The associations of eating rate and metabolic syndrome and its components were largely attenuated after further adjustment for body mass index; however, the association of slow eating with lower odds of high blood pressure (men and women) and hyperglycaemia (men) and that of fast eating with higher odds of lipid abnormality (men) remained statistically significant.

Conclusions: Results suggest that eating rate is associated with the presence of metabolic syndrome and that this association is largely accounted for by the difference in body mass according to eating rate.

\section{INTRODUCTION}

Metabolic syndrome (MetS) is a cluster of physiological risk factors associated with cardiovascular disease and several types of cancer. ${ }^{1}$ Determination of aetiological factors for MetS is required for the establishment of public health strategies to reduce its

\section{Strengths and limitations of this study}

- This study included a large number of participants, used waist circumference in defining metabolic syndrome and analysed data for men and women separately.

- Eating rate was assessed by a self-reported questionnaire.

Information on dietary intake was not obtained.

prevalence and prevent resulting complications. Growing evidence from both observational and interventional studies suggests that dietary habits have a role in the development of $\mathrm{MetS}^{2-4}$ which originates from obesity. Obesity has been extensively investigated in relation to dietary habits including eating rate since 1962, when Ferster et al published a theoretical and practical weight control programme focusing on eating behaviours including eating rate..$^{5}$ Observational studies showed that obese people ate at a faster rate than non-obese people, ${ }^{6}$ and reducing the eating rate may be a simple and effective treatment for obesity. ${ }^{7}$

During the past decade, several crosssectional studies have found a positive association between eating rate and overweight ${ }^{8-11}$ or insulin resistance ${ }^{11-15}$ Similarly, a few longitudinal studies have shown that eating quickly is associated with an increased risk of weight gain $^{1617}$ and type 2 diabetes. ${ }^{18}$ In addition, some cross-sectional studies have reported that fast eating is positively associated with hypertriglyceridaemia and low high-density lipoprotein cholesterol (HDL-C). ${ }^{11}{ }^{14} 19$ Therefore it is conceivable that eating rate might be associated with MetS. To our knowledge, however, only one Korean study cross-sectionally examined eating rate in relation to MetS. ${ }^{20}$ In that study, MetS was defined using body mass index (BMI), rather than waist circumference, and investigated the association in men only. Waist circumference is a component of most MetS 
definitions as a surrogate for central obesity, which can better predict cardiovascular risk. ${ }^{21}$ It is therefore necessary to examine the relationship between eating rate and MetS using waist circumference in both men and women. Here, we investigated cross-sectionally the association between self-reported eating rate and the presence of MetS according to the joint interim statement (JIS) of the International Diabetes Federation and the American Heart Association/National Heart, Lung, and Blood Institute $^{22}$ using a large dataset from health checkups in Japanese men and women.

\section{METHODS AND PROCEDURES Study population}

In Japan, a health checkup under occupational health and safety law is mandatory for all employees. ${ }^{23}$ The law was modified in 2008 when a recommendation for a new national health checkup system focusing on MetS was launched. ${ }^{24}$ Study participants attended the 2011 (calendar year) annual health checkup at the All Japan Labor Welfare Foundation (Tokyo) - a health service centre. Participants were mainly Japanese employees but also included a small number of their dependants and foreign workers-men aged 17-99 and women aged 17-85. Of 297148 participants, we excluded 3660 with a history of myocardial infarction, coronary heart disease or stroke, which might influence both eating rate and MetS. Of the remaining 293488 participants, we included 269297 who reported their eating rate. Of these, we excluded 182487 with missing data for any of the components of MetS (173376 without plasma glucose, 61602 without waist circumference, 43724 without triglyceride, 43401 without HDL-C and 504 without blood pressure; some participants had two or more missing data). The main reason for the large number of participants with missing blood glucose measurement was that $\mathrm{HbAlc}$ was measured instead of blood glucose for those who attended the checkup in a nonfasting condition. Of the remaining 86810 participants, we further excluded 29337 who had a meal within $8 \mathrm{~h}$ before blood was drawn or provided no information about meal time. After further exclusion of 608 participants with missing information on covariates (BMI, smoking status, alcohol consumption and physical activity), 56865 participants (41820 male and 15045 female) remained for analysis.

We did not obtain written informed consent from each participant; instead, we disclosed our intention to carry out the study by putting up posters, giving participants an opportunity to refuse the use of their data for the study. In Japan, informed consent is not necessarily required for observational studies using existing data, as described in the Japanese Ethical Guidelines for Epidemiological Research. ${ }^{25}$ The research protocol was approved by the ethics committee of the National Center for Global Health and Medicine and the ethics committee of Toho University.

\section{Data collection and measurements}

A self-administered questionnaire, which was recommended for specific health examination by the Japanese government (Ministry of Health, Labour and Welfare), ${ }^{26}$ was used to assess eating rate, medical history and health-related lifestyles, including smoking, alcohol consumption and regular physical activity. Eating rate was assessed by asking "How fast is your speed of eating?", with three response options (slow, normal and fast). A trained staff measured height to the nearest $0.1 \mathrm{~cm}$, weight to the nearest $0.1 \mathrm{~kg}$ and waist circumference to the nearest $0.1 \mathrm{~cm}$ at the umbilical level in a standing position. BMI was calculated as the weight in kilograms divided by the squared height in metres. Blood pressure in the sitting position was measured using an automated machine (HEM-907, Omron, Kyoto, Japan). Participants with high blood pressure $(\geq 130 \mathrm{~mm} \mathrm{Hg}$ systolic or $\geq 85 \mathrm{~mm} \mathrm{Hg}$ diastolic) received another measurement and data showing the lower systolic blood pressure were used. A venous blood sample was collected, stored in a cooler at $4^{\circ} \mathrm{C}$ for transportation to an external laboratory (SRL, Tokyo, Japan) and measured within $24 \mathrm{~h}$ of being drawn. Triglyceride level was measured by an enzymatic colorimetric test (Bio Majesty JCA-BM8060, JEOL, Tokyo, Japan) and HDL-C was determined by a direct method (Bio Majesty JCA-BM8060). Plasma glucose level was determined by the hexokinase method (an automatic clinical chemistry analyser JCA-BM9000 series, JEOL, Tokyo, Japan).

\section{Definitions for MetS}

According to the JIS criteria, MetS was defined as three or more of the following risk factors: (1) waist circumference for Asian population $\geq 90 \mathrm{~cm}$ in men and $\geq 80 \mathrm{~cm}$ in women, (2) triglyceride level $\geq 150 \mathrm{mg} / \mathrm{dL}(1.7 \mathrm{mmol} / \mathrm{L})$, (3) HDL-C level $<40 \mathrm{mg} / \mathrm{dL}(1.04 \mathrm{mmol} / \mathrm{L})$ in men and $<50 \mathrm{mg} / \mathrm{dL}(1.3 \mathrm{mmol} / \mathrm{L})$ in women, (4) blood pressure $\geq 130 \mathrm{~mm} \mathrm{Hg}$ systolic or $\geq 85 \mathrm{~mm} \mathrm{Hg}$ diastolic, (5) fasting glucose level $\geq 100 \mathrm{mg} / \mathrm{dL}(5.6 \mathrm{mmol} / \mathrm{L}){ }^{22}$ Participants receiving medication for diabetes, hypertension and dyslipidaemia were considered as having the respective factor, irrespective of measured data.

\section{Statistical analysis}

Participants were divided into three groups according to their eating rate (slow, normal and fast). The characteristics of participants for each eating rate category were expressed as means (SD) for continuous variables and percentages for categorical variables, respectively. Fasting plasma glucose and triglyceride were highly skewed; hence, they were log-transformed and expressed as geometric means (95\% CIs). Trend association was assessed by assigning ordinal numbers (0-2) to the categories of eating rate (slow, normal and fast, respectively) and was tested using linear regression and logistic regression, as appropriate. Multiple logistic regression analysis was used to estimate the ORs with $95 \%$ CI for the presence of MetS across eating rate categories, with normal eating 
rate as the reference. We adjusted for age (continuous, year) in the basic model. In the second model, we further adjusted for smoking status (non-smoker, daily smoker consuming $<20$ cigarettes a day or $\geq 20$ cigarettes a day), physical activity (walking time $<60 \mathrm{~min}$ a day or $\geq 60$ min a day) and alcohol consumption (non-drinker, $<1$ go, 1 to $<2$ go or $\geq 2$ go per day; one go of sake, Japanese traditional beverage, is about $180 \mathrm{~mL}$ of $10-14 \%$ of ethanol and contains $\sim 23 \mathrm{~g}$ of ethanol). In the third model, we added BMI (continuous, $\mathrm{kg} / \mathrm{m}^{2}$ ) to the second model. We performed a likelihood ratio test for the interaction between eating rate and sex. All analyses were done for men and women separately because the interaction was significant ( $p$ for interaction $<0.001$ ). We repeated the above analyses for each component of MetS. A two-tailed $p$ value $<0.05$ was considered statistically significant. All statistical analyses were performed with STATA, V.12.1 (StataCorp, College Station, Texas, USA).

\section{RESULTS}

The prevalence of MetS was $18.5 \%$ in men and $12.8 \%$ in women. Table 1 shows characteristics of the study participants across categories of eating rate. Men who ate quickly tended to be young, whereas women who ate slowly tended to be young. Both men and women who ate quickly consumed a greater amount of alcohol and had significantly higher BMI, waist circumference, triglyceride level and systolic and diastolic blood pressures and lower HDL-C level than those who ate slowly.

The ORs of the presence of MetS across eating rate are shown in table 2. Faster eating was associated with a higher presence of MetS in age- and multivariableadjusted models. The trend was more apparent in men than in women. The multivariable-adjusted ORs $(95 \%$ CI) of MetS for slow, normal and fast rate eating were 0.70 (0.62 to 0.79 ), 1.00 (reference) and 1.61 (1.53 to 1.70 ), respectively, in men ( $\mathrm{p}$ for trend $<0.001$ ), and 0.74 (0.60 to 0.91 ), 1.00 (reference) and 1.27 (1.13 to 1.43 ), respectively, in women ( $p$ for trend $<0.001$ ). Further adjustment for BMI markedly attenuated these associations; however, the association with fast eating and MetS remained statistically significant in men.

Table 3 shows the ORs of the presence of individual MetS components across three categories of eating rate. Central obesity sharply increased with increasing speed of eating; the ORs for slow, normal and fast eating were $0.63,1.00$ (reference) and 1.97, respectively, in men ( $\mathrm{p}$ for trend $<0.001$ ), and $0.73,1.00$ (reference) and 1.44, respectively, in women ( $\mathrm{p}$ for trend $<0.001$ ). High blood pressure and high triglyceride were positively associated with eating rate in both men and women. High fasting plasma glucose and low HDL-C were associated with fast eating in both men and women, but they were associated with slow eating in men only. Additional adjustment for BMI largely attenuated these associations and the significant trend association disappeared. However, the associations of slow eating with decreased odds of high blood pressure (men and women) and hyperglycaemia (men) and those of fast eating with increased odds of abnormal lipid profile (men) remained statistically significant.

\section{DISCUSSION}

In this large population of Japanese men and women, we found that eating rate was positively associated with the presence of MetS, especially in men. Of the components of MetS, the association with abdominal obesity was strongest. These associations were largely attenuated after adjustment for BMI. However, slow eating was associated with a decreased odds of high blood pressure in both men and women and high fasting plasma glucose in men, and fast eating was associated with increased odds of abnormal lipid profiles in men. To the best of our knowledge, this study is the first to report a positive association between eating rate and MetS defined by using waist circumference.

This finding for MetS is consistent with that of a study among Korean men reporting that eating rate was positively associated with MetS, which was defined using BMI instead of waist circumference. ${ }^{20}$ For the MetS components, our study is compatible with some cross-sectional studies showing that eating rate is associated with a higher BMI, ${ }^{8-11}$ and two longitudinal studies showing that eating rate is associated with weight gain. ${ }^{16}{ }^{17}$ In a Korean study that determined the association between eating rate and components of MetS for men and women separately, eating rate was associated with obesity, high blood pressure, hyperglycaemia and abnormal lipid profile in men, whereas it was associated with only obesity in women. ${ }^{11}$ Our results were largely consistent with those in the Korean study (except for blood pressure in women).

Notably, we found that the associations of MetS components with eating rate were largely attenuated after adjustment for BMI, a finding compatible with those of a cross-sectional study in Korea ${ }^{11}$ and a prospective study in Japan. ${ }^{18}$ This result indicates that obesity is a mediator whereby fast eating causes MetS components to deteriorate. We also found, however, that some associations remained statistically significant even after adjusting for BMI (dyslipidaemia with fast eating and hyperglycaemia with slow eating in men, and high blood pressure with slow eating in both men and women). Similarly, the above-mentioned Korean study ${ }^{11}$ reported that a fast rate of eating remained an important determinant for low HDL-C and high fasting plasma glucose after adjustment for BMI in men. Therefore, there may be pathways other than weight gain that underlie the association between eating rate and MetS.

We found that the association between eating rate and MetS was stronger in men than in women, consistent with a previous study in Korea. ${ }^{11}$ Such sex difference may reflect the difference in eating speed of men and women. One study found that women took more bites, had a smaller bite size and slower bites than men in 
Table 1 Characteristics of the study individuals according to eating rates

\begin{tabular}{|c|c|c|c|c|c|c|c|c|}
\hline \multirow[b]{2}{*}{ Characteristics } & \multicolumn{3}{|l|}{ Men $(n=41820)$} & \multirow{2}{*}{$\begin{array}{l}\text { p For } \\
\text { trend* }^{*}\end{array}$} & \multicolumn{3}{|l|}{ Women $(n=15$ 045) } & \multirow{2}{*}{$\begin{array}{l}\text { p For } \\
\text { trend* }^{*}\end{array}$} \\
\hline & Slow & Normal & Fast & & Slow & Normal & Fast & \\
\hline $\mathrm{n}(\%)$ & $2821(6.8)$ & $24893(59.5)$ & $14106(33.7)$ & & $1398(9.3)$ & $9893(65.8)$ & 3754 (24.9) & \\
\hline Age (years) $†$ & $46.9 \pm 12.3$ & $46.9 \pm 10.9$ & $45.0 \pm 10.4$ & $<0.001$ & $43.5 \pm 12.5$ & $47.2 \pm 11.6$ & $46.7 \pm 11.2$ & $<0.001$ \\
\hline Walking time, $\geq 60 \mathrm{~min} /$ day (\%) & 21.8 & 19.0 & 20.6 & 0.004 & 15.5 & 15.0 & 16.1 & 0.798 \\
\hline \multicolumn{9}{|l|}{ Smoking status (\%) } \\
\hline Non-smoker & 61.9 & 55.0 & 56.6 & $<0.001$ & 82.9 & 83.1 & 80.7 & 0.572 \\
\hline $\begin{array}{l}\text { Daily consuming }<20 \\
\text { cigarettes/day }\end{array}$ & 28.6 & 34.6 & 31.3 & & 16.0 & 15.7 & 17.6 & \\
\hline $\begin{array}{l}\text { Daily consuming } \geq 20 \\
\text { cigarettes/day }\end{array}$ & 9.5 & 10.4 & 12.1 & & 1.1 & 1.2 & 1.7 & \\
\hline \multicolumn{9}{|l|}{ Alcohol (\%) } \\
\hline Non-drinker & 30.2 & 26.7 & 26.7 & $<0.001$ & 53.4 & 52.2 & 49.8 & $<0.001$ \\
\hline Drinker $<1$ go/day $\ddagger$ & 33.9 & 35.7 & 34.5 & & 34.2 & 35.9 & 35.5 & \\
\hline Drinker 1 to $<2$ go/day $\ddagger$ & 24.6 & 26.3 & 26.8 & & 9.5 & 9.5 & 11.5 & \\
\hline Drinker $\geq 2$ go/day $\ddagger$ & 11.3 & 11.3 & 12.0 & & 2.9 & 2.4 & 3.2 & \\
\hline BMI $\left(\mathrm{kg} / \mathrm{m}^{2}\right) \dagger$ & $22.4 \pm 3.3$ & $23.4 \pm 3.3$ & $24.6 \pm 3.7$ & $<0.001$ & $21.0 \pm 3.5$ & $21.8 \pm 3.5$ & $22.5 \pm 3.8$ & $<0.001$ \\
\hline Waist circumference $(\mathrm{cm}) \dagger$ & $80.3 \pm 9.2$ & $82.9 \pm 9.0$ & $86.0 \pm 9.8$ & $<0.001$ & $75.5 \pm 9.5$ & $77.7 \pm 9.4$ & $79.6 \pm 9.8$ & $<0.001$ \\
\hline $\begin{array}{l}\text { Systolic blood pressure } \\
(\mathrm{mm} \mathrm{Hg}) \dagger\end{array}$ & $123.5 \pm 15.5$ & $126.1 \pm 15.5$ & $126.7 \pm 15.1$ & $<0.001$ & $113.1 \pm 16.3$ & $117.3 \pm 17.2$ & $117.0 \pm 17.2$ & $<0.001$ \\
\hline $\begin{array}{l}\text { Diastolic blood pressure } \\
(\mathrm{mm} \mathrm{Hg}) \dagger\end{array}$ & $75.2 \pm 11.4$ & $77.3 \pm 11.9$ & $78.0 \pm 12.0$ & $<0.001$ & $69.1 \pm 10.9$ & $71.4 \pm 11.5$ & $71.5 \pm 11.9$ & $<0.001$ \\
\hline $\begin{array}{l}\text { Fasting plasma glucose } \\
(\mathrm{mg} / \mathrm{dL}) \S\end{array}$ & 93.0 (92.5 to 93.6$)$ & 94.4 (94.2 to 94.6$)$ & 94.6 (94.3 to 94.8$)$ & $<0.001$ & 88.1 (87.5 to 88.7$)$ & 89.1 (88.9 to 89.3 ) & 89.5 (89.1 to 89.9$)$ & $<0.001$ \\
\hline Triglyceride $(\mathrm{mg} / \mathrm{dL}) \S$ & 98.3 (96.2 to 100.4$)$ & $103.8(103.0$ to 104.6$)$ & 110.8 (109.8 to 111.9$)$ & $<0.001$ & 67.0 (65.3 to 68.7$)$ & 71.6 (70.9 to 72.3 ) & 74.1 (72.9 to 75.2 ) & $<0.001$ \\
\hline $\mathrm{HDL}-\mathrm{C}(\mathrm{mg} / \mathrm{dL}) \dagger$ & $61.3 \pm 15.3$ & $59.4 \pm 15.0$ & $57.2 \pm 14.3$ & $<0.001$ & $71.4 \pm 15.3$ & $70.5 \pm 15.8$ & $69.3 \pm 15.5$ & $<0.001$ \\
\hline
\end{tabular}




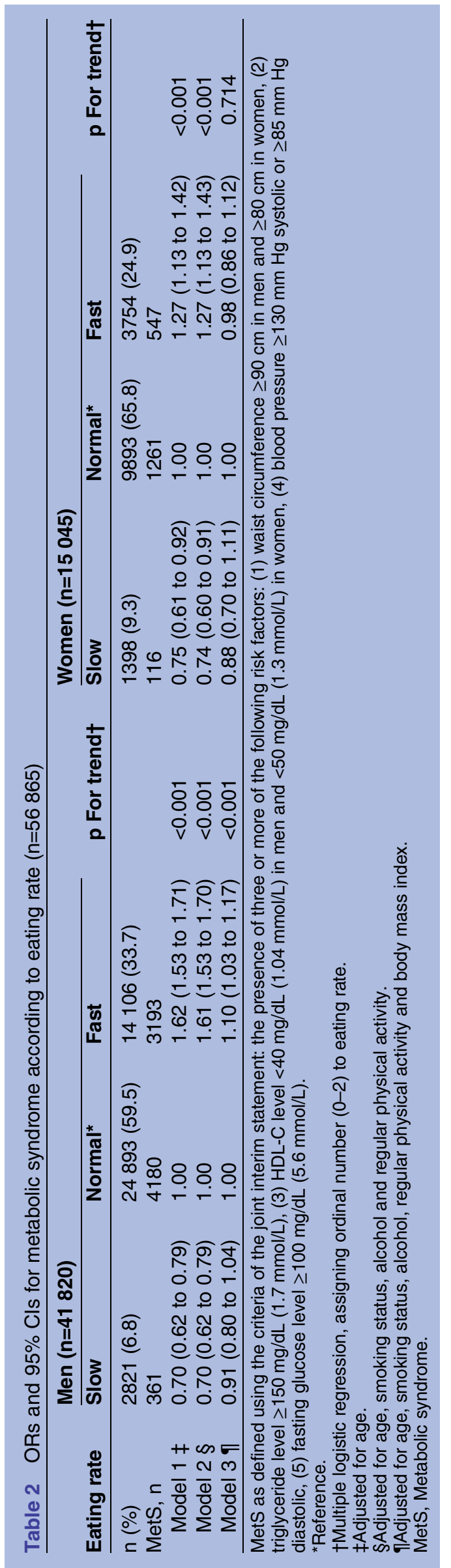

eating the same amount of doughnut, irrespective of body size. ${ }^{27}$ Another study showed that objectively measured eating speed in men with self-reported slow eating was faster than that in women with self-reported fast eating. ${ }^{28}$ Taken together, eating rate may have a greater impact on metabolism in men than that in women.

Although mechanisms by which eating rate influences metabolism have not been fully elucidated, overeating may link fast eating to MetS. Fast eating passes few satiety signals from the mouth to the brain, ${ }^{29}{ }^{30}$ induces less satiation owing to a lack of stomach expansion ${ }^{31}$ and alters the circulating levels of certain gut hormones. ${ }^{32} 33$ In these pathways, fast eating leads to excess energy intake, ${ }^{34}{ }^{35}$ resulting in overweight and MetS. Because fast eating has been associated with obesity even after adjusting for total energy intake, ${ }^{8-11} 14$ other pathways may operate. One study showed that interleukin- $1 \beta$ and interleukin- 6 levels were higher among those who ate quickly than among those who ate slowly, even after accounting for energy intake and BMI. ${ }^{36}$ These cytokines could induce insulin resistance, ${ }^{37} 38$ contributing to high blood pressure via an increased renal sodium and water retention, plasma noradrenaline and sympathetic nervous system activity. ${ }^{39-41}$

The strengths of our study should be mentioned. This study has a large sample size (56865 participants). In addition, body weight, body height and waist circumference were measured by trained technicians, which increased the validity of our study. Nonetheless, the study has several limitations. First, eating rate was selfreported. However, a self-reported eating rate has been shown to be well correlated with that reported by a friend $^{9}$ or one that is objectively measured. ${ }^{28}$ Second, information on dietary intake was not available and thus total energy intake was not considered in the analyses. The adjustment of energy intake, however, might not be appropriate because energy intake may increase with eating rate and thus might act as a mediator rather than confounder. Moreover, eating rate has been associated with body weight independently of energy intake. ${ }^{7-10} 13$ Third, fast-food is an energy-dense dietary source and has been linked to MetS. ${ }^{42}$ Because fast-food is usually consumed quickly, it may confound the association of eating rate with MetS. Fourth, the study participants were mainly workers in various industries including manufacturing $(43.6 \%)$, service $(27.8 \%)$ and transport and telecommunications $(9.9 \%)$, and these figures are similar to those of national survey ${ }^{43}$ However, information on the profession of participants was not available, and thus caution is required when generalising our findings. Fifth, a large number of participants were excluded from the analysis owing to missing data for MetS components. We cannot deny the possibility of bias due to such selective inclusion. Sixth, the crosssectional design precludes any causal inferences about the role of eating rate. Finally, we cannot exclude the possibility of residual confounding and confounding by unmeasured variables. 
Table 3 ORs and $95 \%$ Cls for components of metabolic syndrome according to eating rate $(n=56865)$

\begin{tabular}{|c|c|c|c|c|c|c|c|c|}
\hline \multirow[b]{2}{*}{ Eating rate } & \multicolumn{3}{|l|}{ Men $(n=41820)$} & \multirow[b]{2}{*}{ p For trend $\dagger$} & \multicolumn{3}{|l|}{ Women (n = 15 045) } & \multirow[b]{2}{*}{ p For trend $\uparrow$} \\
\hline & Slow & Normal $^{*}$ & Fast & & Slow & Normal $^{*}$ & Fast & \\
\hline n (\%) & $2821(6.8)$ & $24893(59.5)$ & $14106(33.7)$ & & $1398(9.3)$ & $9893(65.8)$ & 3754 (24.9) & \\
\hline \multicolumn{9}{|c|}{ Central obesity $\ddagger$} \\
\hline Model $1 \S$ & $0.63(0.56$ to 0.71$)$ & 1.00 & 1.98 (1.89 to 2.08$)$ & $<0.001$ & 0.73 (0.64 to 0.83$)$ & 1.00 & $1.44(1.34$ to 1.56$)$ & $<0.001$ \\
\hline Model 2ף & $0.63(0.56$ to 0.70$)$ & 1.00 & 1.97 (1.88 to 2.07$)$ & $<0.001$ & 0.73 (0.64 to 0.83$)$ & 1.00 & 1.44 (1.33 to 1.56$)$ & $<0.001$ \\
\hline \multicolumn{9}{|c|}{ High blood pressure ${ }^{\star *}$} \\
\hline Model $1 \S$ & 0.75 (0.69 to 0.82$)$ & 1.00 & $1.22(1.17$ to 1.27$)$ & $<0.001$ & 0.76 (0.66 to 0.88$)$ & 1.00 & $1.10(1.01$ to 1.21$)$ & $<0.001$ \\
\hline Model 2ף & 0.74 (0.68 to 0.81$)$ & 1.00 & $1.20(1.15$ to 1.26$)$ & $<0.001$ & 0.76 (0.65 to 0.88$)$ & 1.00 & $1.10(1.00$ to 1.20$)$ & $<0.001$ \\
\hline Model 3†† & 0.88 (0.81 to 0.96$)$ & 1.00 & 0.97 (0.93 to 1.02$)$ & 0.645 & 0.85 (0.72 to 0.99$)$ & 1.00 & 0.93 (0.84 to 1.02$)$ & 0.923 \\
\hline \multicolumn{9}{|c|}{ High fasting plasma glucose $\ddagger$} \\
\hline Model $1 \S$ & $0.78(0.71$ to 0.87$)$ & 1.00 & 1.17 (1.12 to 1.23$)$ & $<0.001$ & $1.03(0.85$ to 1.25$)$ & 1.00 & $1.17(1.04$ to 1.31$)$ & 0.035 \\
\hline Model 2ף & 0.78 (0.71 to 0.87$)$ & 1.00 & 1.16 (1.11 to 1.22$)$ & $<0.001$ & $1.03(0.85$ to 1.25$)$ & 1.00 & $1.16(1.03$ to 1.31$)$ & 0.042 \\
\hline Model 3†† & 0.88 (0.80 to 0.98$)$ & 1.00 & 0.99 (0.94 to 1.05$)$ & 0.238 & $1.14(0.94$ to 1.40$)$ & 1.00 & $1.02(0.90$ to 1.15$)$ & 0.536 \\
\hline \multicolumn{9}{|c|}{ High triglyceride§§ } \\
\hline Model $1 \S$ & $0.88(0.80$ to 0.96$)$ & 1.00 & $1.32(1.26$ to 1.38$)$ & $<0.001$ & $0.83(0.67$ to 1.01$)$ & 1.00 & $1.14(1.01$ to 1.28$)$ & 0.002 \\
\hline Model 2ף & 0.90 (0.82 to 0.98$)$ & 1.00 & 1.33 (1.27 to 1.39$)$ & $<0.001$ & 0.81 (0.66 to 1.00$)$ & 1.00 & 1.13 (1.01 to 1.27$)$ & 0.002 \\
\hline Model 3†† & 1.08 (0.98 to 1.19$)$ & 1.00 & 1.07 (1.02 to 1.12$)$ & 0.121 & $0.90(0.73$ to 1.11$)$ & 1.00 & $0.98(0.87$ to 1.11$)$ & 0.753 \\
\hline \multicolumn{9}{|l|}{ Low HDL-Cๆी } \\
\hline Model $1 \S$ & $0.83(0.73$ to 0.96$)$ & 1.00 & 1.34 (1.26 to 1.43$)$ & $<0.001$ & $0.90(0.74$ to 1.09$)$ & 1.00 & $1.11(0.99$ to 1.25$)$ & 0.018 \\
\hline Model 2ף & $0.83(0.73$ to 0.96$)$ & 1.00 & 1.36 (1.28 to 1.45$)$ & $<0.001$ & 0.89 (0.74 to 1.08$)$ & 1.00 & $1.12(1.00$ to 1.26$)$ & 0.011 \\
\hline Model 3†† & $0.97(0.84$ to 1.12$)$ & 1.00 & $1.10(1.03$ to 1.18$)$ & 0.004 & $1.00(0.82$ to 1.22$)$ & 1.00 & $0.96(0.85$ to 1.08$)$ & 0.500 \\
\hline
\end{tabular}

*Reference.

†Multiple logistic regression, assigning ordinal number (0-2) to eating rate.

$\ddagger$ Waist circumference $\geq 90 \mathrm{~cm}$ in men and $\geq 80 \mathrm{~cm}$ in women.

$\S$ Adjusted for age.

ПAdjusted for age, smoking status, alcohol and regular physical activity.

${ }^{* * B}$ Blood pressure $\geq 130 \mathrm{~mm} \mathrm{Hg}$ for systolic or $\geq 85 \mathrm{~mm} \mathrm{Hg}$ for diastolic.

††Adjusted for age, smoking status, alcohol, regular physical activity and body mass index.

$\neq \neq$ Fasting plasma glucose $\geq 100 \mathrm{mg} / \mathrm{dL}$ or under medication.

$\S \S$ Triglyceride $\geq 150 \mathrm{mg} / \mathrm{dL}$ or receiving medication.

Tा7HDL-C $<40 \mathrm{mg} / \mathrm{dL}$ in men, $<50 \mathrm{mg} / \mathrm{dL}$ in women or receiving medication.

$\mathrm{BMI}$, body mass index; HDL-C, high-density lipoprotein cholesterol. 
In conclusion, we found a positive trend association between self-reported eating rate and the presence of MetS in men and women. The association between eating rate and MetS was largely accounted for by the difference in body mass across eating rate. Further research should examine whether reducing eating rate prevents obesity and MetS.

Acknowledgements The authors would like to thank Dr Nobuo Yanagisawa and Dr Takeshi Kawaguchi for coordinating the study.

Contributors SN and KaK designed study and drafted the manuscript. SN, NMP, AN, KeK performed the data analysis. MD collected and interpreted the data. All authors participated in interpretation of the findings, revised the paper critically for important intellectual content and approved the final version to be published. TM and YN provided administrative, technical and material support. SN and TM are guarantors.

Funding This study was supported by the Industrial Health Foundation. Competing interests None.

Ethics approval The research protocol was approved by the ethics committee of the National Center for Global Health and Medicine and the ethics committee of Toho University.

Provenance and peer review Not commissioned; externally peer reviewed.

Data sharing statement No additional data are available.

Open Access This is an Open Access article distributed in accordance with the terms of the Creative Commons Attribution (CC BY 4.0) license, which permits others to distribute, remix, adapt and build upon this work, for commercial use, provided the original work is properly cited. See: http:// creativecommons.org/licenses/by/4.0/

\section{REFERENCES}

1. Eckel RH, Alberti KG, Grundy SM, et al. The metabolic syndrome. Lancet 2010;375:181-83.

2. Gomez-Martinez S, Martinez-Gomez D, Perez de Heredia F, et al. Eating habits and total and abdominal fat in Spanish adolescents: influence of physical activity. The AVENA study. J Adolesc Health 2012:50:403-09.

3. Ilanne-Parikka P, Eriksson JG, Lindstrom J, et al. Effect of lifestyle intervention on the occurrence of metabolic syndrome and its components in the Finnish Diabetes Prevention Study. Diabetes Care 2008;31:805-07.

4. Nanri A, Tomita K, Matsushita Y, et al. Effect of six months lifestyle intervention in Japanese men with metabolic syndrome: randomized controlled trial. J Occup Health 2012;54:215-22.

5. Ferster CB, Nurnberger JI, Levitt EB. The control of eating. 1962. Obes Res 1996;4:401-10.

6. Hill SW, McCutcheon NB. Eating responses of obese and nonobese humans during dinner meals. Psychosom Med 1975;37:395-401.

7. Bellack AS. Behavior therapy for weight reduction. Addict Behav 1975;1:73-82.

8. Otsuka R, Tamakoshi $\mathrm{K}$, Yatsuya $\mathrm{H}$, et al. Eating fast leads to obesity: findings based on self-administered questionnaires among middle-aged Japanese men and women. J Epidemiol 2006;16:117-24.

9. Sasaki S, Katagiri A, Tsuji T, et al. Self-reported rate of eating correlates with body mass index in 18-y-old Japanese women. Int $J$ Obes Relat Metab Disord 2003;27:1405-10.

10. Maruyama K, Sato S, Ohira T, et al. The joint impact on being overweight of self reported behaviours of eating quickly and eating until full: cross sectional survey. BMJ 2008;337:a2002.

11. Lee KS, Kim DH, Jang JS, et al. Eating rate is associated with cardiometabolic risk factors in Korean adults. Nut Metab Cardiovasc Dis 2013;23:635-41.

12. Otsuka $\mathrm{R}$, Tamakoshi $\mathrm{K}$, Yatsuya $\mathrm{H}$, et al. Eating fast leads to insulin resistance: findings in middle-aged Japanese men and women. Prev Med 2008;46:154-59.

13. Radzeviciene L, Ostrauskas R. Fast eating and the risk of type 2 diabetes mellitus: a case-control study. Clin Nutr 2013;32:232-35.
14. Ohkuma $\mathrm{T}$, Fujii $\mathrm{H}$, Iwase $\mathrm{M}$, et al. Impact of eating rate on obesity and cardiovascular risk factors according to glucose tolerance status: the Fukuoka Diabetes Registry and the Hisayama Study. Diabetologia 2013;56:70-7.

15. Shigeta H, Shigeta M, Nakazawa A, et al. Lifestyle, obesity, and insulin resistance. Diabetes care 2001;24:608.

16. Gerace TA, George VA. Predictors of weight increases over 7 years in fire fighters and paramedics. Prev Med 1996;25:593-600.

17. Tanihara S, Imatoh T, Miyazaki M, et al. Retrospective longitudinal study on the relationship between 8-year weight change and current eating speed. Appetite 2011;57:179-83.

18. Sakurai M, Nakamura K, Miura K, et al. Self-reported speed of eating and 7-year risk of type 2 diabetes mellitus in middle-aged Japanese men. Metabolism 2012;61:1566-71.

19. Kral JG, Buckley MC, Kissileff HR, et al. Metabolic correlates of eating behavior in severe obesity. Int J Obes Relat Metab Disord 2001;25:258-64.

20. Shin A, Lim SY, Sung J, et al. Dietary intake, eating habits, and metabolic syndrome in Korean men. J Am Diet Assoc 2009;109:633-40

21. Shen W, Punyanitya M, Chen J, et al. Waist circumference correlates with metabolic syndrome indicators better than percentage fat. Obesity (Silver Spring) 2006;14:727-36.

22. Alberti KG, Eckel RH, Grundy SM, et al. Harmonizing the metabolic syndrome: a joint interim statement of the International Diabetes Federation Task Force on Epidemiology and Prevention; National Heart, Lung, and Blood Institute; American Heart Association; World Heart Federation; International Atherosclerosis Society; and International Association for the Study of Obesity. Circulation 2009;120:1640-5

23. Ministry of Justice, Japan. Industrial Safety and Health Act, Article 66 (Medical Examination). http://www.japaneselawtranslation.go.jp/ law/detail/?id=1926\&vm=\&re= (accessed $28 \mathrm{Jul} 2014)$.

24. Ministry of Health, Labour and Welfare. Specific Health Checkups and Specific Health Guidance. Secondary Specific Health Checkups and Specific Health Guidance. http://www.mhlw.go.jp/english/wp/ wp-hw3/dl/2-007.pdf accessed 28 Jul 2014.

25. The Ministry of Health, Labour and Welfare, Ministry of Education, Culture, Sports, Science and Technology. Ethical guidelines for epidemiological research. 2002. http://www.niph.go.jp/wadai/ ekigakurinri/guidelines.pdf (accessed 28 Jul 2014).

26. Ministry of Health, Labour and Welfare. Questionnaire of Specific Health Checkups. Secondary Questionnaire of Specific Health Checkups. http://www.mhlw.go.jp/seisakunitsuite/bunya/kenkou iryou/kenkou/seikatsu/dl/hoken-program2_02.pdf (accessed $28 \mathrm{Jul}$ 2014) (in Japanese).

27. Hill SW, McCutcheon NB. Contributions of obesity, gender, hunger, food preference, and body size to bite size, bite speed, and rate of eating. Appetite 1984;5:73-83.

28. Ekuni D, Furuta M, Takeuchi N, et al. Self-reports of eating quickly are related to a decreased number of chews until first swallow, total number of chews, and total duration of chewing in young people. Arch Oral Biol 2012;57:981-86.

29. Rolls ET. Sensory processing in the brain related to the control of food intake. Proc Nutr Soc 2007:66:96-112.

30. Morton GJ, Cummings DE, Baskin DG, et al. Central nervous system control of food intake and body weight. Nature 2006;443:289-95.

31. de Graaf C, Blom WA, Smeets PA, et al. Biomarkers of satiation and satiety. Am J Clin Nutr 2004;79:946-61.

32. Kokkinos A, le Roux CW, Alexiadou K, et al. Eating slowly increases the postprandial response of the anorexigenic gut hormones, peptide YY and glucagon-like peptide-1. J Clin Endocrinol Metab 2010;95:333-37.

33. Sobki SH, Zaid AA, Khan HA, et al. Significant impact of pace of eating on serum ghrelin and glucose levels. Clin Biochem 2010;43:522-24.

34. Viskaal-van Dongen M, Kok FJ, de Graaf C. Eating rate of commonly consumed foods promotes food and energy intake. Appetite 2011;56:25-31.

35. Scisco JL, Muth ER, Dong $\mathrm{Y}$, et al. Slowing bite-rate reduces energy intake: an application of the bite counter device. J Am Diet Assoc 2011:111:1231-35.

36. Mochizuki K, Misaki Y, Miyauchi R, et al. A higher rate of eating is associated with higher circulating interluekin-1beta concentrations in Japanese men not being treated for metabolic diseases. Nutrition 2012;28:978-83.

37. Besedovsky H, del Rey A, Sorkin E, et al. Immunoregulatory feedback between interleukin-1 and glucocorticoid hormones. Science 1986;233:652-54 
38. Matsuki T, Horai R, Sudo K, et al. IL-1 plays an important role in lipid metabolism by regulating insulin levels under physiological conditions. J Exp Med 2003;198:877-88.

39. Yatabe MS, Yatabe J, Yoneda M, et al. Salt sensitivity is associated with insulin resistance, sympathetic overactivity, and decreased suppression of circulating renin activity in lean patients with essential hypertension. Am J Clin Nutr 2010;92:77-82.

40. Facchini FS, DoNascimento C, Reaven GM, et al. Blood pressure, sodium intake, insulin resistance, and urinary nitrate excretion. Hypertension 1999;33:1008-12.
41. Pollare $\mathrm{T}$, Lithell $\mathrm{H}$, Berne $\mathrm{C}$. Insulin resistance is a characteristic feature of primary hypertension independent of obesity. Metabolism 1990;39:167-74.

42. De Vogli R, Kouvonen A, Gimeno D. The influence of market deregulation on fast food consumption and body mass index: a cross national time series analysis. Bull World Health Organ 2014;92:99-107A

43. Ministry of Health, Labour and Welfare. Special Survey on Industrial Safety and Health. http://www.mhlw.go.jp/bunya/rdouk jun/ 4 zeneisei11/h23.html (accessed 28 Jul 2014) (in Japanese). 